Meta

Journal des traducteurs

Translators' Journal

\title{
Un Manolito Gafotas modélico: la purificación y corrección en la traducción al inglés de la serie española
}

\section{Carolina Travalia}

Volume 64, numéro 2, août 2019

URI : https://id.erudit.org/iderudit/1068200ar

DOI : https://doi.org/10.7202/1068200ar

Aller au sommaire du numéro

Éditeur(s)

Les Presses de l’Université de Montréal

ISSN

0026-0452 (imprimé)

1492-1421 (numérique)

Découvrir la revue

Citer cet article

Travalia, C. (2019). Un Manolito Gafotas modélico: la purificación y corrección en la traducción al inglés de la serie española. Meta, 64(2), 393-417. https://doi.org/10.7202/1068200ar
Résumé de l'article

Les livres de la série espagnole Manolito Gafotas ont été traduits en plus de vingt langues. Une des traductions les plus récentes en anglais (2008) est éditée quatorze ans après la publication du premier livre de la série espagnole. Dans cet article, la traductrice du deuxième et du troisième livre de la série (2009 et 2010, respectivement) analysera comment cette oeuvre a été traduite de manière " acceptable " selon les normes de la culture cible conservatrice. Sous la pression de la rédactrice en chef, plusieurs références dans les livres originaux considérées inappropriées ou potentiellement négatives pour les jeunes lecteurs ont été nuancées ou éliminées. À cet égard, des références au tabac, à l'alcool, aux fonctions physiologiques, aux comportements irrespectueux, ainsi que des mentions de certains groupes ethniques et des allusions qui auraient pu être interprétées d'une manière sexuelle ont été minimisées. En outre, le but pédagogique des livres a été exacerbé ; il en est résulté des changements comme la standardisation de la langue familière, une des caractéristiques les plus proéminentes des livres originaux. L'autrice examinera comment les changements utilisés s'alignent sur les tendances de la traduction de la littérature jeunesse en général et spécifiquement comment elles reflètent les valeurs conservatrices associées à la littérature jeunesse aux États-Unis. La conséquence la plus importante de ces changements est la création d'un nouveau Manolito modèle. 


\title{
Un Manolito Gafotas modélico: la purificación y corrección en la traducción al inglés de la serie española
}

\author{
CAROLINA TRAVALIA \\ Hobart and William Smith Colleges, Geneva, Estados Unidos \\ travalia@hws.edu
}

\section{RÉSUMÉ}

Les livres de la série espagnole Manolito Gafotas ont été traduits en plus de vingt langues. Une des traductions les plus récentes en anglais (2008) est éditée quatorze ans après la publication du premier livre de la série espagnole. Dans cet article, la traductrice du deuxième et du troisième livre de la série (2009 et 2010, respectivement) analysera comment cette œuvre a été traduite de manière «acceptable » selon les normes de la culture cible conservatrice. Sous la pression de la rédactrice en chef, plusieurs références dans les livres originaux considérées inappropriées ou potentiellement négatives pour les jeunes lecteurs ont été nuancées ou éliminées. À cet égard, des références au tabac, à l'alcool, aux fonctions physiologiques, aux comportements irrespectueux, ainsi que des mentions de certains groupes ethniques et des allusions qui auraient pu être interprétées d'une manière sexuelle ont été minimisées. En outre, le but pédagogique des livres a été exacerbé; il en est résulté des changements comme la standardisation de la langue familière, une des caractéristiques les plus proéminentes des livres originaux. L'autrice examinera comment les changements utilisés s'alignent sur les tendances de la traduction de la littérature jeunesse en général et spécifiquement comment elles reflètent les valeurs conservatrices associées à la littérature jeunesse aux États-Unis. La conséquence la plus importante de ces changements est la création d'un nouveau Manolito modèle.

\begin{abstract}
The books of the Spanish series Manolito Gafotas have been translated into more than twenty languages. One of the most recent translations is the English one (2008), published fourteen years after the first book of the series came out in Spain. In this article, the English translator of the second and third books of the series will analyze how an acceptable work according to the standards of the conservative target culture was created. With pressure from the editor, many references in the original books considered to be inappropriate or to have a potentially negative influence on young readers were reduced or eliminated. In that regard, references to alcohol, tobacco, violence, bodily functions, disrespectful behavior, as well as mentions of certain ethnic groups and allusions that might be interpreted in a sexual manner were downplayed. At the same time, the pedagogical aspect of the books was enhanced leading to such changes as the standardization of the colloquial language, one of the most salient characteristics of the original books. The author will examine how the changes in the English version are in line with the tendencies of the translation of children's literature in general and specifically reflect the politically correct values associated with children's literature in the United States. The most important consequence of these changes is the creation of a new, model Manolito.
\end{abstract}

\section{RESUMEN}

Los libros de la serie española Manolito Gafotas se han traducido a más de veinte lenguas. Una de las traducciones más recientes es la traducción al inglés (2008), publicada catorce años después de que se editara el primer libro de la serie en España. En este trabajo, la 
traductora al inglés del segundo y tercer tomo de la serie (2009 y 2010, respectivamente) examinará la manera en la que se creó una obra aceptable según los estándares de la culta meta conservadora: los Estados Unidos. Bajo presión de la editorial, se redujeron o eliminaron muchas referencias de los libros originales que se consideraban inapropiadas o una mala influencia para los jóvenes lectores. En este sentido, se minimizaron referencias al alcohol, al tabaco, a la violencia, a las funciones corporales, al comportamiento irrespetuoso, así como menciones de ciertos grupos étnicos y alusiones que se podían interpretar de forma sexual. La autora de este trabajo examinará cómo la versión inglesa se alinea con las tendencias de la literatura infantil en general y reflejan específicamente los valores políticamente correctos asociados con la literatura infantil en los Estados Unidos. La consecuencia más importante de estos cambios es la creación de un nuevo Manolito modélico.

\section{MOTS CLÉS/KEYWORDS/PALABRAS CLAVE}

traduction de la littérature jeunesse, Manolito, censure, le politiquement correct, ÉtatsUnis comme culture cible

translation of children's literature, Manolito Four-Eyes, censorship, political correctness, USA as target culture

traducción de literatura infantil, Manolito Gafotas, censura, corrección política, EE.UU. como cultura meta

\section{Introducción}

Los libros españoles de Manolito Gafotas ${ }^{1}$, escritos por Elvira Lindo, han gozado de un éxito notable no solo en España, sino también en muchos países extranjeros. De hecho, la serie se ha traducido a más de veinte lenguas. La primera versión extranjera que se realizó fue la francesa, solo tres años después de la publicación del primer libro de la serie (1994). Una de las últimas traducciones, en cambio, ha sido la estadounidense, cuyo primer volumen se editó en 2008.

Lindo intentó introducir la serie en los Estados Unidos en los años noventa, pero fue rechazada por varias editoriales, según la autora, "porque se traducen muy pocos libros en Estados Unidos, porque hay pocos lectores de español en las editoriales y porque el libro no traspasaba la barrera de lo políticamente correcto en este país $»^{2}$. Efectivamente esta serie no se ajustaba a los valores morales del sistema literario infantil de los Estados Unidos. Por fin, en 2007 la agente estadounidense de Lindo encontró una editorial dispuesta a publicar los libros (Marshall Cavendish) con la condición de que se mitigaran las referencias al castigo corporal, a elementos escatológicos, al alcohol, al tabaco y a diferentes tradiciones religiosas (Lindo 2013) ${ }^{3}$.

Las obras originales constituían un crossover (Lindal 2016) al dirigirse a un lector implícito triple (los niños, los adolescentes y los adultos). Con «mensajes cargados de sarcasmo e ironía al lector adulto [,] [su autora] es transgresora al romper con los códigos de lo políticamente correcto dentro de la Literatura Infantil y Juvenil (LIJ)» (Marcelo Wirnitzer 2015: 32). Pionera en España al buscar el deleite tanto de los niños como de los adultos, Lindo deja de ver a estos últimos como intermediarios que deciden qué libros deben leer los niños para convertirlos en participantes plenos de la lectura. Sin embargo, la editorial estadounidense, que se dedica sobre todo a publicar series de ficción infantiles, decidió dirigir la versión traducida exclusivamente a niños de entre ocho y doce años porque este público encajaba bien con la voz y la mezcla de amigos y familia de Manolito. Así se convirtió en una obra infantil propiamente dicha. Asimismo, el protagonista pasó a tener diez años en vez de ocho 
porque consideraban que su actitud y sus acciones eran más propias de un niño de esa edad. También se actualizó el texto para que no pareciera anticuado, de modo que las historias en inglés tienen lugar a finales de la década 2000-2010 en vez de la segunda mitad de los años noventa ${ }^{4}$.

Hasta la fecha, se han traducido al inglés únicamente los primeros tres libros de la serie, que está compuesta por ocho tomos ${ }^{5}$. Nosotros realizamos la traducción del segundo y del tercer libro (2009 y 2010), mientras que el primero (1994) fue traducido por Joanne Moriarty (2008). En un amplio análisis de la traducción al inglés del primer libro, Marcelo Wirnitzer califica de llamativa la censura que se aplica al lenguaje soez, a elementos tabú (como el SIDA), a las drogas y a la violencia física, motivada por las convenciones de los EE.UU. que «obligan a ejercer un elevado grado de intervencionismo en el texto, de manipulación» (Marcelo Wirnitzer 2015: 75-76).

En el presente trabajo, examinaremos una serie de cambios que se realizaron en la traducción al inglés cuya función era la de crear un TM aceptable (daremos cabida a los tres tomos, aunque nuestra perspectiva en cuanto al primero será más limitada). Veremos que dichos cambios son el resultado sobre todo de imposiciones de censura por parte de la editorial. Comprobaremos que, si bien las imposiciones de censura ayudan a crear un TM que sigue las tendencias de la traducción de la literatura infantil en general y que se adhiere a los valores conservadores de los libros para niños en los Estados Unidos, el resultado es un protagonista y unas historias en muchos aspectos irreconocibles.

\section{Metodología}

En nuestro análisis descriptivo orientado al proceso, examinaremos cómo entraron en conflicto nuestras metas como traductora, basadas en nuestra visión del futuro lector (Oittinen 2000), y el paternalismo (Lorenzo 2014) y la censura (Fourie y Dowell 2002) impuestos por la editorial. Estas imposiciones estaban basadas, a su vez, en las normas didácticas de la sociedad meta que rigen la traducción de la LIJ (Desmidt 2006). Veremos cómo se adaptó un acercamiento de aceptabilidad frente a uno de adecuación (Toury 1995) y cómo se aplicaron los criterios que aseguran el éxito del texto en la cultura meta (Shavit 2006). Consideraremos las decisiones de la editorial y otras limitaciones de nuestra labor como traductora para arrojar luz sobre el proceso de traducción. En los dos niveles principales del texto, la historia/trama y el discurso (O’Sullivan 2005), analizaremos los siguientes cambios que sirvieron para crear un producto meta apto para el sistema literario infantil de los EE.UU.: la atenuación de comportamientos inapropiados, la supresión de conducta irrespetuosa, la omisión de posibles alusiones sexuales, la eliminación de elementos políticamente incorrectos y la estandarización del registro. Por último, examinaremos un cambio cuya función era asegurar la comprensión del público de llegada: la corrección del discurso.

Nos basaremos en el trabajo de Cámara Aguilera (2014), quien, siguiendo el modelo de House (2004), analiza el proceso de traducción al inglés del segundo tomo, Pobre Manolito. Su propósito principal es determinar si los cambios debidos a los criterios de "protección» establecidos por los adultos están justificados o no. Esta autora concluye lo siguiente: 
los [cambios] aquí producidos carecen en su mayoría de justificación, ya que alejan al receptor meta de la historia expresada en el texto origen: reflejar la realidad social de una determinada época [finales del siglo], en una determinada cultura [la española]. (Cámara Aguilera 2014: 39)

Si bien esta estudiosa confirma que nuestro objetivo como traductora de «trasladar su sentido del humor a través de un personaje entrañable por su mezcla de perspicacia e inocencia [...] se cumple a grandes rasgos», sostiene que una segunda meta nuestra de «dar a conocer la cultura española» no se realiza (Cámara Aguilera 2014: 39) ${ }^{6}$.

En su trabajo, Cámara Aguilera (2014) analiza las referencias culturales, incluida la comida, los nombres de los personajes, los lugares y las tradiciones y elementos "políticamente incorrectos», además de los castigos físicos, el alcohol, el tabaco, lo escatológico, lo ideológico-moral y la intertextualidad cultural. Dado que nuestro enfoque es la censura en el proceso, no cubriremos referencias culturales o elementos de intertextualidad que no fueron sometidos a una purificación. Aunque el traslado de estos aspectos al inglés da lugar a cambios dignos de comentar, no se ajustan al propósito y al alcance de este trabajo. Lo que aportamos al estudio de Cámara Aguilera (2014) es un elemento clave para cualquier análisis del proceso de traducción: información directa sobre la toma de decisiones y la comunicación entre la traductora y los editores. Con esta información, profundizaremos en el análisis de los cambios debidos a la censura. Asimismo, brindaremos una mayor consideración a las modificaciones del lenguaje. Con nuestra perspectiva única y nuestra aportación lingüística, esperamos contribuir a un entendimiento mejor de la esencia de las traducciones al inglés de Manolito Gafotas.

Antes de entrar en el análisis, pasaremos revista a los parámetros principales de la traducción de la LIJ, consideraremos las implicaciones de la censura en EE.UU., así como nuestra relación con Manolitos Gafotas primero como lectora y luego como traductora.

\section{La traducción de la LIJ}

La literatura infantil y juvenil se distingue de la literatura para adultos por su comunicación asimétrica creada a partir del hecho de que los autores, que son adultos, escriben para un grupo, los niños, del que no forman parte ellos mismos. También los libros para niños se diferencian de los libros tradicionales en que van dirigidos a un público dual (Oittinen 2006; Van Coillie 2006; O’Connell 2006; etc.). En otras palabras, se escriben para niños, pero son los padres y otros adultos los que eligen los libros y, a menudo, los que los leen en voz alta. Por esta razón, los autores de libros infantiles se ven obligados a crear un producto que atraiga a los niños y que, al mismo tiempo, satisfaga las expectativas de los adultos.

Esta asimetría se vuelve aún más pronunciada cuando se traducen libros de esta categoría: son adultos quienes traducen libros escritos por adultos que van dirigidos a niños. Hay otro grupo de adultos que influye en el proceso, quizá más que cualquier otro ya mencionado. Nos estamos refiriendo a los intermediarios, que incluyen agentes literarios y editores. Estos profesionales deciden qué libros se han de traducir y qué aspectos de dichos libros son apropiados para el público de llegada (Van Coillie y Verschueren 2006: 36). También ejercen presión sobre los traductores para que respeten los valores, principios y tabú de la cultura meta (Reiss 1982: 7). 
Las obras infantiles sirven no solo para divertir sino también para enseñar. Según O’Sullivan (2002), esta doble función, literaria y pedagógica, es la que distingue la literatura infantil de las otras ramas de la literatura. No solo vale para entretener al niño, sino también para educarlo y socializarlo según las normas de la sociedad. En los libros traducidos el aspecto de la enseñanza desempeña un papel especial. Desmidt resume las normas didácticas y pedagógicas de la literatura infantil traducida:

A children's book, in terms of didactic norms, should enhance the intellectual and/or emotional development of the child and set good, worthy examples; it should, according to the pedagogical norms, be adjusted to the language skills as well as the conceptual knowledge of the child [...]. (Desmidt 2006: 86)

Las traducciones en general oscilan entre los dos polos definidos por Toury (1995): la adecuación y la aceptabilidad. Las obras de LIJ traducidas, en concreto, favorecen la aceptabilidad o adaptación a la cultura meta sobre la adecuación o conservación de las normas del texto origen. Según Shavit, para conseguir la aceptabilidad de una obra infantil, el traductor ha de asegurar que el libro sea apropiado para el niño y que este lo comprenda:

- Tiene[...] que ajustar el texto para que sea apropiado y útil para el niño, según lo que la sociedad denomine "bueno para el niño";

- Ha[...] de adaptar la trama, los personajes y la lengua al nivel de comprensión y habilidades de lectura del niño (Shavit 2006: 26).

Shavit (2006: 26) añade que el traductor puede permitirse muchas libertades, con tal de que respete estos dos principios.

Las normas educativas y sociales llevan a los traductores y editores de obras infantiles a adoptar una serie de estrategias por las que eliminan o pulen elementos potencialmente inapropiados para la cultura meta, ya que anticipan una posible reacción negativa por parte de los intermediarios. O'Sullivan (2005: 81-82) distingue entre dos niveles en los que los cambios pueden llevarse a cabo: el de la historia o trama y el del discurso. El primer nivel representa las acciones, los personajes y los lugares e incluye representaciones de violencia y referencias escatológicas. El segundo, por su parte, se refiere a cómo se cuenta la historia y comprende la corrección del discurso creativo (incluidas palabras mal escritas intencionalmente) y la estandarización del registro o el nivel del habla. A través de cambios de este tipo, el texto se conforma a las normas sociales y estilísticas de la cultura de llegada.

Ya sea por motivos de comprensión, de pedagogía o de presión social, el traductor actúa de forma paternal cuando introduce elementos que en el texto de partida eran implícitos, explicando alusiones que imagina que serán difíciles de entender por el lector meta y sustituyendo o eliminando aspectos que considera dañinos para este mismo (Lorenzo 2014: 36). El traductor no es el único que puede ejercer esta manipulación sobre el TM. Los otros agentes involucrados en el proceso de traducir, como los editores, también toman decisiones cuya finalidad es proteger al público juvenil o hacer que su experiencia como lectores sea más fácil. A lo que Lorenzo (2014) denomina "paternalismo», otros estudiosos en el pasado han designado como purificaciones (Klingberg 1986; Oittinen 2000; Aziz Qader 2010). 


\section{La censura en la LIJ en EE.UU.}

En los EE.UU. se exportan muchos más libros infantiles de los que se importan. En general, los libros traducidos representan un riesgo mayor para las editoriales que los libros de autores de habla inglesa (O’Sullivan 2005: 68). En los EE.UU. y en el Reino Unido, únicamente entre el uno y el dos por ciento de los libros destinados a los niños son traducciones (O’Sullivan 2002: 39) frente al cuarenta y dos por ciento en España, traducidos principalmente del inglés. Los libros que constituyen ese porcentaje minúsculo en EE.UU. tienden a adaptarse a la cultura y los valores de este país (Stan 1997).

Como nos recuerda Pascua Febles (2015), toda traducción está sujeta a una ética que refleja el momento histórico-social en que se engendra. Esta ética pertenece a la traducción social que dicha autora define como «una forma de colaboración, de equilibrio entre lo relativo de la individualidad y la universalidad, ya que los valores éticos deben tender a lo universal» (Pascua Febles 2015: 37). Como veremos a continuación, en los EE.UU. la literatura infantil arrastra una serie de cánones difíciles de derrumbar y existe una fuerte ética en lo que atañe a este género.

Según Fourie y Dowell (2002: 107), la censura es la práctica de ocultar o suprimir elementos considerados objetables. La censura puede darse en cualquier momento del proceso de producción, publicación o distribución. Si ocurre antes de la publicación se llama pre-censura (Ingram 2000; Khan 1999 ${ }^{8}$ ). Sin embargo, hasta mediados del siglo pasado ni siquiera se discutían los temas de la libertad intelectual de los niños o la censura, ya que los adultos involucrados en la producción de libros infantiles daban por sentado su papel de proteger a los niños. Estos adultos compartían un código implícito que dictaba que no se debían incorporar en los libros para niños elementos tabú, incluidos actos violentos, palabrotas, referencias a la sexualidad o una imagen negativa de los adultos (MacLeod 1983: 31). Sin embargo, con la influencia de los movimientos sociales y nuevas normas más liberales que llegaron con los años sesenta, algunos autores se rebelaron contra estas reglas tácitas. Dentro de este Nuevo Realismo, Judy Blume, por ejemplo, escribió sobre la sexualidad, Susan Eloise Hinton, sobre la violencia de las bandas y Alice Childress, sobre las drogas y la homosexualidad (West 1996/2004: 685). Como reacción, se inició enseguida una lucha conservadora contra estos y otros libros considerados inmorales, que todavía perdura hoy en día.

Aunque otros países anglosajones también han experimentado este intento de purga en el mundo de la literatura infantil, el ataque contra las obras del Nuevo Realismo ha sido más pronunciado en los EE.UU. (West 1996/2004: 686). En este país, por ejemplo, ciertos grupos religiosos han protestado fuertemente los libros de Harry Potter por su presentación de brujas y hechizos (Booth 2011: 29-30). Hunt (1997: 96) denuncia la censura «invisible» que existe tanto en EE.UU. como en el Reino Unido ejercida por las editoriales en sus procesos de selección. Anticipando una reacción negativa por parte del público, estas entidades solo acceden a editar obras que consideran aceptables para su sociedad.

A pesar de la pre-censura que existe por parte de las editoriales, cada año numerosos libros infantiles y juveniles se prohíben en los EE.UU. The Horn Book Magazine, una revista estadounidense dedicada a la literatura infantil y juvenil, publica una lista anual de los libros más prohibidos por diferentes bibliotecas públicas, escuelas y otras organizaciones. Junto a los libros más censurados del 2015 se citan los motivos por su censura. Estos incluyen el lenguaje ofensivo, el sexo, la homosexualidad, el ser 
transgénero, la perspectiva religiosa, la violencia y el ser inapropiado para el grupo de edad al que va dirigido. En el caso de Fifty Shades of Grey ${ }^{9}$, por ejemplo, una de las razones que se ofrece por prohibirlo es «que los adolescentes querrán probar [los actos de sexo]» $»^{10}$.

Además de proteger la inocencia del niño mediante la exclusión de elementos tabú, los libros infantiles en EE.UU. tienen la responsabilidad de promover el bienestar de la sociedad eliminando referencias a comportamientos negativos que los jóvenes lectores puedan imitar. Por último, los libros de este género suelen presentar un inglés correcto, sin palabras mal escritas o repeticiones típicas del habla oral, un léxico y sintaxis estándar y un registro no demasiado coloquial. En vez de representar cómo los niños hablan de verdad, tienden a exhibir cómo deberían hablar.

\section{Manolito Gafotas: de TO a TM}

Como ya hemos mencionado en el apartado 1, Lindo tuvo dificultades para introducir los libros de Manolito Gafotas en los EE.UU. La serie no presentaba las características exigidas por la tradición de literatura infantil en este país y no existían obras similares en este sistema. O’Sullivan (2005) y Shavit (2006) explican que las obras infantiles traducidas solo tendrán éxito si se corresponden con un modelo existente en la cultura de llegada. Diary of a Wimpy Kid (2006) de Jeff Kinney ${ }^{11}$ era posiblemente la serie más parecida. Sin embargo, a pesar de presentar a un joven protagonista anti-héroe que relata su vida en un tono coloquial con referencias satíricas involuntarias, estas obras no contenían aspectos como el castigo corporal, el alcohol y el tabaco o referencias políticamente incorrectas. Shavit (2006: 28) achaca el requisito del modelo existente a la tendencia del mundo de la literatura infantil a solo aceptar lo conocido y lo convencional y puntualiza que, cuando el texto meta es demasiado poco familiar, es preciso añadir o eliminar ciertos elementos para adaptarlo a los modelos de la tradición meta. La editorial que por fin aceptó publicar la serie, Marshall Cavendish, reconoció esta necesidad y exigió que los traductores la respetaran.

Cuando recibimos el encargo de traducir el segundo tomo, nuestro objetivo principal era reproducir nuestra experiencia al leer Manolito Gafotas para el futuro lector. Según Oittinen (2000), la manera en que el traductor experimentó el texto que está traduciendo cuando realizó su propia lectura del mismo determina cómo la desea compartir con el futuro lector o lector implícito. El traductor se imagina cómo será el futuro lector, basándose en su concepción de la infancia y del niño para la que recurre a los recuerdos personales y las convenciones de la sociedad (Oittinen 2000: 4-5), y cómo será la experiencia del futuro lector cuando lea la obra traducida.

Nuestra propia lectura de los libros de Manolito Gafotas como hablante extranjera de veinte años de edad implicó una relación de adulto donde pudimos apreciar las múltiples capas de la narración y el humor. Las referencias culturales nos permitieron aprender sobre los lugares, la comida, los comportamientos y las costumbres de los niños españoles. No obstante, el elemento más útil desde el punto de vista pedagógico fue la riqueza del lenguaje coloquial con elementos de oralidad. Nuestro futuro lector no solo se iba a divertir con las historias y aprender sobre la cultura española, sino que también se iba a identificar con Manolito por su modo de percibir el mundo de los adultos, a veces enigmático y lleno de contradicciones y como resul- 
tado, frustrante, y por su forma de hablar coloquial y a veces incorrecto. Por lo tanto, era de suma importancia conservar los elementos mencionados, guiando el texto más hacia el polo de la adecuación que hacia el de la aceptabilidad.

No obstante, dado que no tradujimos el primer libro, heredamos los nombres de los personajes y los lugares y el registro estándar. No podíamos efectuar cambios al respecto, ya que era necesario mantener continuidad entre el primer libro y todos los posteriores. Estas restricciones resultaron frustrantes desde el primer momento. Asimismo, la editorial tenía otras prioridades, tales como crear una obra con las siguientes características con respecto al TO:

- más accesible, esto es, menos extranjera, para el lector;

- más aceptable para sus padres y otros intermediarios;

- más estándar en términos del habla.

El resultado fue una oposición continua donde los borradores que entregábamos nos llegaban de vuelta con múltiples cambios en lo que concernía a la trama, las referencias a comportamientos negativos y elementos tabú y el lenguaje. No perdamos de vista, por consiguiente, que la mayoría de los cambios en las traducciones al inglés de Manolito Gafotas que presentamos a continuación son el reflejo de la voluntad de la editorial llevada a cabo por nosotros los traductores, al menos en lo que respecta a la segunda y tercera entregas.

\section{Análisis traductológico comparado}

\subsection{Nivel de la historia/trama}

\subsubsection{Atenuación de comportamiento inapropiado}

Como en todos los países, la literatura infantil en los EE.UU. pretende enseñar al niño lo correcto y protegerlo de lo malo. Por ende, en la traducción de Manolito Gafotas se atenuaron los comportamientos inapropiados para poder presentar un modelo más positivo para el joven lector.

Cámara Aguilera sostiene que determinados elementos inapropiados en los libros originales, como el castigo físico, el alcohol, el tabaco y lo escatológico desempeñan un papel importante en la recreación de la clase obrera española a finales del siglo pasado:

Manolito Gafotas es una obra que hunde sus raíces en el modus vivendi de la clase obrera española a finales del siglo XX. En ese proceso de crear una obra literaria a partir de una realidad social, la autora se va a servir de un amplio abanico de recursos [...]. Elvira Lindo diseña su proyecto en torno a una gran piedra angular: el castigo físico. Junto a este elemento central e imprescindible para la recreación social de la época que quiere llevar a cabo, utiliza otros elementos igualmente importantes para el logro de sus objetivos y que adquieren mayor fuerza por su interrelación con el anterior. Dichos elementos son: el alcohol, el tabaco y lo escatológico. Todo ello, cimentado a través de una mezcla de humor e ironía y aderezado con algunas pinceladas ideológicas o intertextuales hacen de esta obra, sin duda, un referente de la LIJ española contemporánea. (Cámara Aguilera 2014: 31)

Las collejas que la madre de Manolito le proporciona cuando se porta mal constituyen una parte importante de la trama de estos libros. En la introducción del 
primer libro, Manolito define el concepto de colleja: «La colleja es una torta que te da una madre, o en su defecto cualquiera, en esa parte del cuerpo humano que se llama nuca» (Lindo 1994: 9). La manera en la que Manolito describe las collejas es divertida e irónica. Nuestro protagonista afirma que su madre es experta en collejas y en múltiples ocasiones se refiere a la calidad de los golpes, como por ejemplo, en Pobre Manolito: «La colleja cayó implacable. Fue un buen trabajo por su parte, lo reconozco» (Lindo 1995: 61). Manolito ofrece una descripción exagerada y satírica de todos los diferentes tipos de collejas que componen el reportorio de su madre, como, por ejemplo, las de efecto retardado, o sea, «[...] las que te duelen a la media hora aproximadamente» (Lindo 1994: 6).

La violencia en la forma del castigo corporal es un tema delicado hoy en día en muchos países, los EE.UU. entre ellos. La editorial consideró las referencias a las collejas potencialmente ofensivas para el público actual de los EE.UU. y juzgó preferible no presentar el castigo corporal bajo una luz graciosa. Por lo tanto, en la versión al inglés, se sustituyeron las collejas por lectures (sermones) o chewing somebody out (echar una bronca), un acto de purificación y paternalismo:

1) A él le consoló su madre y a mí la mía me dio una colleja de las de efecto retardado, de las que te duelen a la media hora aproximadamente.

(Lindo 1994: 13)

a) His mom consoled him and mine chewed me out (one of those delayed-reaction lectures that I don't realize has started until half an hour in).

(Lindo 1994/2008: 11, traducido por Moriarty)

Estas sustituciones permitieron que se mantuviera la idea del regaño y la clasificación de Manolito, incluido the delayed-reaction lecture, sin el elemento de violencia. No obstante, se sacrifica el aspecto satírico, dado que los sermones no empiezan a doler un tiempo después, como un golpe en la nuca. También es cierto que excluir las collejas de la traducción le resta gracia y posiblemente información histórica al texto (en el pasado el castigo corporal era una práctica normal). Es importante mencionar que desde 2007 el castigo corporal está prohibido en España ${ }^{12}$. Si se publicaran en España hoy en día los libros de Manolito, tal vez resultarían igual de ofensivas las referencias a las collejas. De hecho, Lindo afirma que si los escribiera hoy en día, no incluiría el concepto de la colleja ${ }^{13}$. Por eso, no se trata solo del país receptor, sino también y, quizá de forma más importante, del momento de publicación.

Se omitieron otras alusiones a la violencia en el texto por razones de corrección política. Según Manolito, él tiene pesadillas no por la violencia que ve en la televisión, sino por la violencia que ve en su casa. Propusimos 2a) como traducción en inglés de 2). La editora escribió: «Sorry, don't want to say his home is 'violent' for pc reasons» y se cambió a $2 b)$ :

2) Luego dicen que si tengo pesadillas y que si estoy atacado de los nervios porque veo la televisión. En mi casa, la realidad supera cualquier programa de sucesos sangrientos.

(Lindo 1996: 80)

a) And they're always saying I have nightmares because I watch violent stuff on TV. Ha! My house is way violenter than any bloody TV show.

(Traducido por Caroline Travalia) 
b) And they're always saying I have nightmares because I watch violent stuff on TV. Ha! My apartment is way scarier than any TV show.

(Lindo 1996/2010: 55, traducido por Caroline Travalia)

Otra referencia a la violencia que se eliminó ocurre cuando el Imbécil dice que quiere quedarse con Manolito en casa en vez de acompañar a su madre y a la Luisa de compras, su madre responde de esta forma: «Vámonos -le dijo a la Luisa- y que se maten entre ellos» (Lindo 1995: 82). Si bien estas palabras no tenían un significado literal, la editorial estimó que la idea de que los niños se «mataran» era demasiado violenta, y en la versión al inglés truncamos la oración: «Let's go' she said to Luisa» (Lindo 1995/2009: 80, traducido por Travalia).

Se suavizó igualmente una mención a la tortura. En un momento dado, Manolito califica de aterrador el aspecto de la sita Asunción, que llevaba un bastón y arrastraba una pierna:

3) Eso le daba un aspecto bastante aterrador, como esas mujeres enormes de las películas que tienen secuestrados a cientos de niños inocentes y dedican su vida a torturarlos en masa y les amenazan con el bastón y luego se ríen con unas carcajadas que hacen temblar los muros de su mansión diabólica.

(Lindo 1995: 97)

a) That made her look pretty scary, like one of those humongous women in the movies who kidnap hundreds of innocent kids and dedicate their lives to threatening them with their canes, and then they laugh so hard the walls of their diabolic mansions shake.

(Lindo 1995/2009: 97, traducido por Travalia)

En la traducción inglesa, se dejó fuera la referencia a la tortura. A diferencia de las collejas, estos últimos dos ejemplos no son manifestaciones de violencia en el texto, sino solo alusiones a ella, como un medio de lograr la comicidad a través del recurso de la exageración. No obstante, se juzgaron igualmente inapropiadas para el público norteamericano.

Además de la violencia, se mitigaron también las funciones corporales. Aunque es un tema popular dentro de la literatura infantil estadounidense actual donde títulos como Everyone Poops, The Gas We Pass, Adventures of Captain Underpants y The Adventures of Super Diaper Baby tienen mucho éxito, usarlo en exceso puede considerarse vulgar para el público meta. También es conveniente señalar que algunos de los títulos mencionados han sido objetivo de tentativas de censura por promover comportamientos antisociales (Booth 2011: 28).

Manolito se orina encima en diferentes ocasiones en el texto original, o bien porque le da la risa, o bien porque tiene miedo. Le ocurre, por ejemplo, cuando roba en la tienda de la Señora Porfiria y también después del robo, cuando su madre está a punto de regañarle:

4) Cuando por fin [...] tuvimos [a las madres] cerca yo me meé. Lo que es la vida, hacía un momento que me meaba de risa y ahora de miedo.

(Lindo 1995: 21)

a) Life is really something. A minute before I was peeing in my pants from laughing so hard, and now I was peeing in my pants from being so scared.

(Lindo 1995/2009: 16, traducido por Travalia) 
En la versión inglesa se redujeron las menciones a la orina de tres a dos, con la siguiente nota de la editora: «Too much with peeing in pants for our edition. A little is okay, and I think this works with cut». La orina se suprime en otra ocasión en el libro. La perra de la Luisa, la Boni, sigue a Manolito al colegio y cuando la sita la descubre en el aula y está a punto de regañar a Manolito, él se orina encima. En la traducción al inglés, la referencia a la orina desaparece por completo:

5) Lo confesaré: mientras me levantaba sentí que un poco (pero muy poco) de pis me manchaba los pantalones.

(Lindo 1995: 173)

a) I'll admit: I thought about not saying anything.

(Lindo 1995/2009: 129, traducido por Travalia)

Cámara Aguilera (2014: 36) se percata de la desaparición de la orina en la versión en inglés y afirma que, aunque desconoce los motivos de la supresión, sospecha que es el resultado de una conducta paternalista. Efectivamente, la editora eliminó la referencia a la orina con la siguiente nota en el margen: «Per earlier note, peeing in pants feels too young for our 10 year old Manolito and off for our audience».

De igual manera, siempre que aparece en el texto meta se traduce mearse como to pee o to wet, términos menos vulgares que su correspondiente, to piss. Cámara Aguilera (2014: 35) critica esta decisión: «la traductora debiera haberse planteado las razones que llevaron a la autora a escoger un término y no otro antes de tomar una decisión de traducción». El motivo de este cambio es que la editorial consideró el término to piss equivalente demasiado vulgar para el público infantil.

Resulta importante señalar que la gran mayoría de las referencias escatológicas se mantuvieron. Por ejemplo, de las diecinueve veces que aparece mearse en los tres volúmenes, solo dos se eliminaron en la traducción al inglés. Asimismo, se conservó el capítulo sobre los pedos de Bernardo, el padrino de Manolito («Los cochinitos», Pobre Manolito) y el capítulo en el que el Imbécil hace de cuerpo en casa de la Luisa después de las dos fiestas de cumpleaños del Orejones, atascando en las dos ocasiones la tubería («Envidia Podrida», ¡Cómo molo!). De las ocho menciones de la palabra caca en los primeros tres libros, seis se mantuvieron. De esas seis menciones, solo la mitad se expresa a través de términos menos vulgares: (go to the) bathroom (Linda 1996/2010: 90, 104) y presents (Linda 1996/2010: 104). Por último, cada una de las nueve ocasiones en las que se utiliza el vocablo pedo en el texto origen se reprodujo en la versión inglesa con el vocablo equivalente: fart. De nuevo, la editorial consideraba aceptables las referencias escatológicas siempre que aparecieran en cantidades limitadas. Se temía que, presentadas en abundancia, estas alusiones vulgares llevaran a los padres a rechazar los libros por ser socialmente inapropiadas.

Otro elemento que se atenuó para apoyar el principio de que el texto debe servir como modelo son las referencias al alcohol y al tabaco. Al estar prohibido el consumo de alcohol para los menores de veintiún años en EE.UU., resulta delicado excederse en las alusiones al vino y licor en una obra infantil, aunque sean adultos quienes están consumiendo las bebidas alcohólicas. Al igual que con los elementos escatológicos, la editorial permitió la presencia del alcohol en la versión al inglés pero en con tal de que no fuera abundante. De las ocho veces que se menciona el vino en los tres tomos analizados originales, siete se mantuvieron y solo una vez se omitió. En una ocasión se redujo el número de botellas de vino que los adultos habían consumido de tres a dos y en otra, los tintos de verano de cuatro a tres. Se conservaron las dos veces que 
se habla de una copa y la única mención del champán. Con el licor la editorial fue más cauta: su vermú de los sábados (Lindo 1995: 70) se convirtió en their morning coffee (Lindo 1995/2009: 67). En el capítulo «La Tía Melitona» de Pobre Manolito, se eliminaron nueve de las once referencias al anís y se sustituyeron las otras dos por Coke. En esta escena, se desperdicia la descripción irónica de Manolito de cómo su Abuelo se sacrifica bebiéndose botellas de anís para que Manolito las pueda usar como instrumento en el colegio («La Tía Melitona», Pobre Manolito). En esta misma escena, Manolito utiliza las botellas de anís para hacerle a su abuelo un cóctel palomita (al cual añade dos gotas de agua para contentar a su madre). Aquí Cámara Aguilera (2014: 34) no acierta al afirmar que la editorial no entiende la gracia de esta escena: «Que Manolito pueda coger una botella de alcohol y con ella prepararle una bebida a su abuelo, que lo haga habitualmente y que a nadie le resulte especialmente llamativo es algo que la editorial no termina de entender». La editora de la traducción inglesa reconoció que era gracioso, pero explicó que un niño no puede hacer cócteles en una obra infantil en EE.UU.: «This is very funny but we can't have him making drinks».

En muchas ocasiones en la traducción al inglés la editorial pidió la sustitución de alusiones al alcohol por otras a la cocacola o al café. En una escena en particular de Pobre Manolito, muchos vecinos de Carabanchel Alto se reúnen en el bar El Tropezón para ver el partido Madrid-Barça. El dueño le pregunta a cada cliente antes del comienzo del partido: ¿Cuántos vinos te vas a tomar? (Lindo 1995: 25). En la versión inglesa se sustituyó coffee por vino: How many cups of coffee...? (Lindo 1995/2009: 20, traducido por Travalia). Cámara Aguilera (2014: 34) explica cómo el resultado de la censura de esta escena «bajo ningún concepto representa la realidad social española descrita con tanta maestría por Elvira Lindo». Esta autora también percibe lo paradójico de cambiar tintos de verano (Lindo 1995: 41-42) a glasses of wine (Lindo 1995/2009: 38), si consideramos que la última contiene más alcohol (Cámara Aguilera 2014: 34).

Es igualmente interesante señalar que se refirió a El Tropezón a veces como a un bar y a veces como a café, para quitarle énfasis a la idea de que en el establecimiento sirvan alcohol. Estas omisiones y sustituciones protegen al lector estadounidense, pero al mismo tiempo ocasionan una pérdida de información sobre la cultura española y de gracia en el texto. Estos son solo unos ejemplos de la presión ejercida por los intermediarios y en particular, la editorial, de la que nos advierten Van Coillie (2006) y Reiss (1982).

Al igual que con el alcohol, la editorial juzgó excesivas las menciones a los cigarrillos y a los puros en el texto origen. En el sueño de Manolito que él cuenta en Pobre Manolito, la editorial usó el azúcar como sustituto del tabaco, como vemos en el Cuadro 1:

CuAdro 1

Substitutos del tabaco

\begin{tabular}{|c|c|}
\hline $\begin{array}{l}\text { Pobre Manolito } \\
\text { (Lindo 1995) }\end{array}$ & $\begin{array}{c}2 n d \text { Volume } \\
\text { (Lindo } 1995 / 2009, \text { traducido por Travalia) }\end{array}$ \\
\hline un puro (p. 64) & a candy cigar (p. 61) \\
\hline hacía con el humo unos anillos enormes (p. 64) & pink smoke rings (p. 61) \\
\hline la ceniza (p. 64) & pink ash (p. 61) \\
\hline $\begin{array}{l}\text { [...] me dijo [mi padre] que el día que quisiera fumar } \\
\text { que lo hiciera delante de él dentro de los muros de } \\
\text { mi casa, sin que me viera nadie [...]. (p. 58) }\end{array}$ & $\begin{array}{l}{[\ldots] \text { [my dad] said the day I wanted to smoke }} \\
\text { that I should do it in my own apartment that } \\
\text { I bought with my own money [...]. (p. 58) }\end{array}$ \\
\hline
\end{tabular}


Se convirtieron las menciones al tabaco en el Cuadro 1 en referencias inocentes al azúcar que no incitan a los niños a fumar. Como reacción a la traducción literal de nuestro primer borrador, la editora escribió: «Need to change or cut for our audience. Touchy subject». Al final se eliminó la parte del comentario del padre que si Manolito quiere fumar algún día que lo haga delante de él, y por lo tanto esa ironía. Al mismo tiempo se especificó que Manolito compraría con su propio dinero la casa (o apartment en inglés) donde fumaría. Con esta aclaración se deja claro que el padre no consentirá las acciones negativas de su hijo, aunque sea de forma pasiva. De este modo se suprime la ironía en la versión original de que el padre quiera que él lo haga delante de él y en su casa, ya que la mayoría de los padres les dicen lo contrario a sus hijos.

Se dejaron todas las menciones del cigarro en el capítulo «La conciencia tranquila» de Pobre Manolito, donde la madre de Manolito lo descubre sujetando un cigarro que en realidad pertenece a Yihad y sus amigos de formación profesional. Cámara Aguilera (2014: 34) explica que era necesario mantener el tabaco aquí: "para caracterizar a determinados personajes que se encuentran rozando la marginalidad o mostrando una actitud desafiante o subversiva, es necesario respetar la presencia del tabaco». También es cierto que Manolito es castigado por sujetar el cigarro de tal forma que los lectores reciben un mensaje claro: no se permite la asociación de los niños con el tabaco.

$\mathrm{Al}$ alcohol y al tabaco, hay que sumar una mención a las pastillas para dormir: «[...] mis padres se fueron a acostar después de darle [a mi abuelo] dos cafés y pastillas» (Lindo 1996: 63). En la traducción al inglés, se trunca la oración: «My parents went off to bed» (Lindo 1996/2010: 62, traducido por Travalia). Como resultado, la ironía de ofrecerle a alguien una bebida con cafeína seguida por una medicina que da somnolencia, dos ingredientes que se contradicen, desaparece. La editorial quería evitar que los niños estadounidenses pensaran que es aceptable tomar somníferos.

Con estas modificaciones y omisiones se evita transmitir un ejemplo de conductas negativas y así se refuerza la intención didáctica del texto.

\subsubsection{Supresión de conducta irrespetuosa}

Recordemos que Desmidt (2006) afirma que las traducciones de obras infantiles deben establecer buenos modelos para sus lectores. Manolito y sus amigos exhiben a veces una falta de respeto hacia los mayores y hacia sus coetáneos. En la versión al inglés se intentó moderar esta conducta, al estimar que constituía un mal ejemplo para los lectores. Algunos ejemplos de los libros originales son:

a) En vez de llamarle a su hermano por su nombre, Manolito usa el mote Imbécil;

b) Manolito insulta al Imbécil: ¿Y ahora con qué rellenamos el frasco, niño inútil? (Lindo 1995: 53);

c) Susana le saca la lengua a la profesora y dice a sus espaldas: Calla, foca (Lindo 1995: 136).

En cuanto a a), Manolito en inglés llama a su hermano Bozo, que también significa tonto pero que es un nombre común para un payaso y, a diferencia de Imbécil, tiene connotaciones jocosas y cariñosas. En b), en vez de llamar a su hermano useless (inútil), lo llama genius: And now what do we fill the bottle with, Genius? (Lindo 1995/2009: 50, traducido por Travalia). Genius es un término positivo y si bien en este contexto Manolito lo usa de forma sarcástica, es menos peyorativo que el agravio directo useless boy. Imbecile, la transferencia del mote español Imbécil, o Idiot, la 
traducción más común del mismo, integrarían un insulto. Para evitar que los lectores estadounidenses tuvieran esta referencia de comportamiento negativo que pudieran reproducir, Moriarty y la editorial optaron por el apodo más afectuoso, Bozo.

Por último, en la traducción inglesa de c), la Susana le saca la lengua a la profesora, pero no dice nada: "And Susana, taking advantage of the fact that Miss Asunción wasn't looking, stuck out her tongue» (Lindo 1995/2009: 139, traducido por Travalia). En otras palabras, cierta rebelión y falta de respeto se mantuvo en el ejemplo de la Susana. Sin embargo, la editorial censuró la traducción original sugerida para Calla, foca (Shut up, whale), al considerar que sería demasiado ofensiva y capaz de fomentar la imitación entre los jóvenes lectores estadounidenses.

Por otro lado, hay que reconocer que se incluyó la palabra sucks (en el inglés coloquial significa ser despreciable) en el texto meta: It sucks taking care of the Bozo (Lindo 1995/2009: 50, traducido por Travalia). Este término es típico del habla de los jóvenes en Estados Unidos y se considera vulgar.

\subsubsection{Omisión de posibles alusiones sexuales}

La siguiente estrategia que contribuye a crear un texto aceptable es la omisión de posibles alusiones sexuales. En otras palabras, se eliminaron elementos que la editorial temía que pudieran interpretarse de forma sexual al traducirse al inglés, a pesar de que no tenían tal naturaleza en el texto de partida.

Como sabemos, Shavit (2006) opina que la traducción de un texto infantil ha de ser «buen[a] para el niño». Esto incluye mantener la inocencia del niño y protegerlo de temas adultos. Con respecto al sexo, es improbable que el niño vea ciertos elementos del texto como insinuaciones sexuales. Sin embargo, los padres, al leer los libros con sus hijos, podrían malinterpretar determinados aspectos $\mathrm{y}$, por ende, censurar el libro.

En la versión original, Susana, la amiga de Manolito, recibe el mote de Susana Bragas-sucias. En el primer libro, Manolito explica por qué se llama así:

Su madre [...] decía que las bragas se le manchaban de tierra aunque llevara el chándal y que haría falta que vinieran a España científicos de todo el mundo para saber por qué unas bragas que salían blancas de casa por la mañana dentro de un chándal, a la hora de comer se habían vuelto negras. (Manolito Gafotas: 64-5)

A Susana, la única chica del grupo íntimo de amigos de Manolito, le gusta jugar fuera y, como resultado, se mancha de tierra. Sin embargo, en la traducción al inglés, se cambió su nombre a The One-And-Only Susana (Susana, la única) porque se temía que la idea de las bragas sucias se pudiera interpretar de forma sexual. El mote inglés es genérico y podría aplicarse a cualquiera de los personajes. Tampoco revela información sobre la personalidad de Susana y, lo que es más importante, no aporta humor al texto.

Otro cambio que se realizó para evitar un malentendido sexual es el sueño de Manolito en «Soñando con sirenas» (¡Cómo Molo!). Todos los hombres, incluido Manolito, están cautivados por la novia noruega de su tío Nicolás. La última noche de su estancia en Madrid, ella y Nicolás dejan que Manolito duerma en la cama con ellos. Antes de dormirse, Manolito le comenta a su tío que su novia parece una sirena: «Es verdad lo que dijiste, tío Nicolás, parece una sirena pero muy grande [...]» (Lindo 1996: 73). 
Esa noche Manolito se orina en la cama: «Aquella noche soñé con sirenas noruegas en el lago de la Casa de Campo. Debió de ser por eso que pasó lo que pasó. [...] me meé» ((Lindo 1996: 73). Su tío le consuela: «-Natural- dijo mi tío Nicolás. -Eso pasa siempre que uno sueña con sirenas» (Lindo 1996: 73). Para evitar que los lectores pensaran que Manolito había tenido una polución nocturna, en la traducción al inglés la editorial eliminó los últimos cuatro párrafos de este capítulo. Se pierde, por tanto, la referencia a que Manolito duerme con ellos, sueña o se orina en la cama.

Es interesante notar que Manolito y su abuelo duermen juntos en la versión inglesa, a pesar de las posibles implicaciones de molestia sexual. En al menos una de las numerosas traducciones de esta serie de libros (desconocemos cuál) se censuró este aspecto (Lindo 2013). Es verdad que en Pobre Manolito se borró la siguiente frase del abuelo que se consideraba potencialmente insinuante: Manolito, pásate a la cama a calentarme los pies (Lindo 1995: 29). En inglés permanece solo: Manolito, warm up my feet (Lindo 1995/2009: 24). Cámara Aguilera (2014: 37) opina que «en ese compartir espacio y en esa entrañable relación entre nieto y abuelo que la autora nos devela a lo largo de la obra, no cabe encontrar un sentido malintencionado a esa frase [...]».

A pesar de que las obras españolas carecían de cualquier implicación sexual, la editorial juzgaba estas modificaciones necesarias para conservar la inocencia del niño lector en lo que concierne al sexo y evitar que los padres se escandalizaran y prohibieran la lectura de los libros.

\subsubsection{Eliminación de elementos no políticamente correctos}

En el apartado 2 vimos el concepto de paternalismo dentro de la traducción de la LIJ. Existe un tipo de intervencionismo o paternalismo específico, el de la traducción políticamente correcta. Mayoral (1997: 98) define esta cuestión, introducida por Newmark (1993: 65), como «evitar deliberadamente el uso de palabras y expresiones que puedan resultar ofensivas, discriminatorias o perjudiciales para grupos sociales, raciales, étnicos, mujeres, animales, etc.». La sensibilidad hacia las diferencias de raza, religión, orientación sexual y estatus, que muchos califican de corrección política, se valora mucho en la sociedad norteamericana actual. A los niños se les enseña a respetar al «otro» mediante la representación positiva de las diferencias o la eliminación completa de las mismas. Siguiendo esta idea, en la traducción al inglés de Manolito Gafotas se eliminó una serie de referencias posiblemente ofensivas para el público estadounidense.

Uno de los primeros cambios dentro de esta práctica que se llevó a cabo fue el nombre propio del amigo de Manolito, Yihad. El término Yihad en los años 90 constituía una referencia a algo lejano de la realidad española, la guerra contra los enemigos del Islam. Resultaba gracioso porque el amigo de Yihad tiene una personalidad bélica. Sin embargo, en el mundo post-once de septiembre, cuando se editaba el primer libro en EE.UU., este país lidiaba con la amenaza del terrorismo islámico por un lado y con la discriminación generalizada contra los musulmanes por el otro. Moriarty y la editorial optaron por un nombre carente de implicaciones religiosas: Ozzy. Este apodo del nombre de pila Oswald se asocia en la cultura popular con la rebelión contra las normas de la sociedad, una actitud apropiada para nuestro personaje Yihad, gracias a la figura del cantante roquero Ozzy Osbourne. Sin embargo, la referencia no es obvia para el lector y carece de un doble sentido humoroso.

La raza, en particular, es un tema que recibe mucha atención en EE.UU. En la literatura en general, se percibe una tendencia a querer evitar ofender a personas de 
distintas razas y no darle ideas al joven lector de cómo puede insultar a otros. El tema de la raza es aun más delicado en los libros infantiles, ya que, como sabemos, estos deben ser un modelo para los niños. Por esta razón, en la versión inglesa de Manolito Gafotas, la editorial suprimió las siguientes alusiones:

6) Primero sin hacer ruido y treinta segundos más tarde al estilo de los indios de Arizona: saltando unos por encima de los otros.

(Lindo 1995: 88)

a) [...] first without making a sound, and thirty seconds later like Madrid soccer fans, jumping all over each other.

(Lindo 1995/2009: 87, traducido por Travalia)

7) 'hay más bares que chinos'

(Lindo 1995: 26)

a) [OMITIDO]

(Lindo 1995/2009: 21, traducido por Travalia)

La frase original en español de 6) implica que los indios son salvajes, una insinuación tabú hoy en día. 7) contiene la expresión idiomática española haber más _- que chinos que actualmente es ofensiva por utilizar de forma satírica a la población más grande del mundo como punto de comparación. Asimismo, existen referencias a celebraciones o grupos religiosos que, en la traducción, se vuelven neutras o se eliminan por completo:

8) un Hare Krishna

(Lindo 1995: 71)

a) OMITIDO

(Lindo 1995/2009: 68, traducido por Travalia)

9) Navidades

(Lindo 1995: 129)

a) Holiday time

(Lindo 1995/2009: 132, traducido por Travalia)

Después de que Manolito le corte el pelo al Imbécil dejándole calvo con una colita detrás, dice que se parece a un Hare Krishna (8). No solo la editorial lo consideró una burla del grupo religioso, señalando «Best to leave out for US audience», sino que juzgó que los niños del público meta no estarían familiarizados con dicho grupo y, por consiguiente, no comprenderían la comparación. Incluso una mención a las Navidades se suprimió (9). A diferencia de los ejemplos en 6) y 8), 9) no tiene un propósito humorístico y, por lo tanto, no posee la potencial de ofender a ningún grupo. La editorial insistió en que sustituyéramos Navidades por un término más general (Holiday time) para que los lectores de otras religiones no se sintieran incómodos por no celebrar las Navidades. Esta sustitución es un ejemplo de la traducción social que respeta las normas actuales de la sociedad meta, concepto delimitado, como hemos visto en el apartado 4, por Pascua Febles (2015). Sin embargo, la historia se desarrolla en España y habría sido interesante que los lectores estadounidenses hubieran apreciado a partir del texto que la religión católica es una parte fundamental de la cultura española.

Aparte de la raza y la religión, se atenuaron otras referencias posiblemente ofensivas, como, por ejemplo, cuando se menciona a un enano: «Entre el polvo que habían 
levantado las ruedas al frenar nos pareció ver a un enano que se bajaba del coche» (Lindo 1996: 7). El enano en este caso es un niño y Manolito emplea este vocablo porque es más expresivo y gracioso. En la versión inglesa, se sustituyó enano por Hobbit (Lindo 1996/2010: 4, traducido por Travalia), en vez de la traducción literal, dwarf. Hobbit es un personaje ficticio y, por lo tanto, según la editorial, no resulta irrespetuoso para personas de baja estatura.

Con todos estos cambios cuyo propósito era reducir la posibilidad de ofender a ciertos grupos de personas, es sorprendente que se mantuviera el apodo despectivo del personaje, Gafotas (en inglés Four-eyes). Suponemos en el primer libro que Moriarty y la editorial utilizaron el apodo equivalente en inglés porque da nombre a toda la serie y se refleja en los dibujos. Asimismo, Manolito presenta el mote como un aspecto positivo de su identidad. Está orgulloso de él y reconoce que gracias a haberse apropiado de él, sus enemigos ya no pueden usarlo en su contra:

Antes de tener un mote yo lloraba bastante. Cuando un chulito se metía conmigo en el recreo siempre acababa insultándome y llamándome cuatro-ojos o gafotas. Desde que soy Manolito Gafotas insultarme es una pérdida de tiempo. (Lindo 1994: 8)

Sin embargo, si no se lee el primer capítulo de Manolito Gafotas donde el protagonista explica su relación con su apodo, puede aparecer ofensivo dentro del mundo protegido y puritano de la LIJ en EE.UU. En una bitácora de Time Out New York Kids una madre norteamericana critica a la editorial por utilizar el término Four-eyes porque, según ella, consiente el uso de apodos insultantes:

Unfortunately Manolito Four Eyes is a character that could be taken as a mockery to children who must wear glasses due to vision impairment. There's [sic] many children nowadays that suffer from this from a very early age. The nickname Big Ears Lopez given to his friend is kind of unsettling as well. This may be entertaining in Spain but the fact that this book may prompt children to mock others by using nicknames for their physical disadvantages, should stop the distribution of it in the US. ${ }^{14}$

Esta cita muestra la sensibilidad que existe hoy en día en los EE.UU. con respecto a ciertos temas, así como el deseo de proporcionar a los niños únicamente asociaciones positivas por miedo a que ellos imiten los elementos negativos o que estos les disminuyan la autoestima.

A partir de la eliminación de todos estos aspectos considerados potencialmente ofensivos se crea un texto políticamente correcto en el que no se hace mención a diferentes grupos de personas y se evitan referencias religiosas. Se conserva, sin embargo, el apodo del protagonista por ser un elemento clave de las historias y la identidad del mismo.

\subsection{Nivel del discurso}

\subsubsection{Estandarización del registro}

Consideremos ahora los cambios al nivel del discurso del texto. Los libros originales exhiben un español moderno y coloquial que da la impresión de ser espontáneo, como la lengua hablada. Rico Martín (2001) comenta el aspecto oral de su diálogo:

Articula de forma magistral lenguaje y vida pues se trata, al fin y al cabo, del discurso propio de un niño, donde la escritora cuida al máximo los detalles expresivos resul- 
tando, en algunas ocasiones, algo repetitivo y con procedimientos propios de la narrativa oral. ${ }^{15}$

Sus numerosos fraseologismos no solo enriquecen el lenguaje, sino que también «le dan ese citado sabor castizo con expresiones como "se marchó por la puerta grande", en clara referencia al mundo de los toros, y, por otro lado, con expresiones creadas por Lindo como "mola un pegote" o la famosa colocación "el mundo mundial"» (Marcelo Wirnitzer 2015: 32). El tono informal de Manolito narrador y protagonista se manifiesta a través de su léxico, sintaxis, morfología y fonética, típicos de un niño de clase obrera de las afueras de Madrid. Algunos ejemplos de su léxico coloquial son los siguientes, que vienen del primer tomo (Lindo 1994):

\section{CUADRO 2}

\section{Léxico coloquial}

\begin{tabular}{|l|l|}
\hline \multicolumn{2}{|c|}{ Manolito Gafotas (Lindo 1994) } \\
\hline molar (p. 9) & cacho (p. 57) \\
\hline modorra (p. 23) & chollo (p. 15) \\
\hline rollo (p. 10) & garbeo (p. 16) \\
\hline chasco (p. 27) & pegas (p. 91) \\
\hline
\end{tabular}

Existen igualmente numerosos usos sintácticos típicos que constituyen errores del discurso coloquial:

- Le por les: «Le quité los capuchones a los superrotuladores [...]» (Lindo 1994: 92).

- Laísmo: «[...] su madre se puso como una hiedra (que se subía por las paredes) gritándola: "Mañana no sales, ni mañana ni nunca"» (Lindo 1994: 63).

También observamos otros aspectos sintácticos y morfológicos coloquiales, todos del primer libro (Lindo 1994):

\section{CUADRO 3}

Otros aspectos sintácticos y morfológicos coloquiales

\begin{tabular}{|l|l|}
\hline \multicolumn{2}{|c|}{ Manolito Gafotas (Lindo 1994) } \\
\hline Joé (p. 18) & {$[\ldots]$ di que el otro día [...] (p. 36) } \\
\hline El mundo mundial (p. 134) & Ah, se siente (p. 107) \\
\hline Tenían unas cacho piernas (p. 57) & Anda, vete, salmonete (p. 50) \\
\hline
\end{tabular}

Asimismo, aparecen varios elementos fonéticos coloquiales, sobre todo la eliminación de la $d$ intervocálica en la forma masculina del participio pasado, como observamos en estos ejemplos de ¡Cómo molo! (Lindo 1996):

- descarao (Lindo 1996: 37);

- pasmao (Lindo 1996: 39);

- asfixiao (Lindo 1996: 64);

- mosqueao (Lindo 1996: 88).

O'Sullivan (2005: 89) pone de relieve que el discurso coloquial a menudo es víctima de las normas literarias del sistema meta: «Colloquial language as used by young 
people may also be omitted or adapted in translation in line with the prevalent literary norms». Como es de esperar, la naturaleza coloquial de los libros de Manolito Gafotas se disminuye en la traducción inglesa. Era importante para la editorial presentar un modelo de corrección lingüística a los jóvenes lectores, siguiendo la tendencia de la LIJ en EE.UU. Por lo tanto, la versión de este país presenta un inglés estándar sin muchos usos léxicos, sintácticos o morfológicos propios del inglés americano coloquial. La versión inglesa del primer libro carece de elementos coloquiales típicos, como la palabra like precedida por el verbo to be y como sinónimo de decir: por ejemplo «Then he was like, 'see you later'». Tampoco hace uso la traducción inglesa del primer libro del verbo to go con el mismo sentido de decir: por ejemplo, Then he goes, 'see you later', ni recurre a representaciones fonéticas coloquiales como woulda, shoulda, gotta, 'cause, etc.

En los libros dos y tres, introdujimos algunas palabras y estructuras coloquiales como las siguientes que aparecen en 2 nd Volume:

CUADRO 4

Palabras y estructuras coloquiales

\begin{tabular}{|l|l|l|l|}
\hline \multicolumn{4}{|c|}{ 2nd Volume (Lindo 1995/2009, traducido por Travalia) } \\
\hline Palabra/estructura & Por... & Palabra/estructura & Por... \\
\hline dude (p. 14) & - & woulda (p. 12) & would have \\
\hline wanna (p. 7) & want to & They'd be like (p. 8) & They would say \\
\hline coulda (p. 12) & could have & 'cause (p. 36) & because \\
\hline 'em (p. 12) & them & gotta (p. 63) & got to \\
\hline
\end{tabular}

Sin embargo, la editorial deseaba que estos libros usaran un inglés estándar, al igual que el primer libro. De ahí que se eliminaran muchos usos coloquiales que originalmente habíamos incluido en el borrador de las traducciones, como la muletilla like: «We talk on the phone [like] three or four times a day» (Lindo 1996/2010: 70, traducido por Travalia). Otros elementos coloquiales que se suprimieron fueron el pronombre posesivo plural their en lugar del singular his/her; así, por ejemplo:

10) Luisa says that years ago, every kid had an invisible guardian angel at [their] his side.

(Lindo 1995/2009: 10, traducido por Travalia)

También se suprimió el verbo to be en indicativo en la prótasis de la oración hipotética y se sustituyó por el modo en subjuntivo:

11) If I [wasn't] weren't a fan of Real I'd be the disgrace of the family.

(Lindo 1995/2009: 19, traducido por Travalia)

Estas correcciones hacen que el inglés del texto meta sea correcto y modélico, reforzando el propósito pedagógico del mismo, característica esencial de la literatura infantil según O’Sullivan (2002). Sin embargo, también llevan al empobrecimiento del personaje de Manolito. Con su forma de hablar, que se aproxima al modo de expresarse de un adulto, este personaje se vuelve menos dinámico y menos creíble. Nuestro lector implícito tiene menos posibilidad de divertirse e identificarse con este Manolito gracias a su modo de hablar. De forma irónica, sin embargo, este Manolito 
elocuente se alinea más con las expectativas que los lectores estadounidenses tienen de los niños protagonistas en LIJ, ya que un lenguaje correcto es una característica de este género que valora presentar modelos positivos a sus jóvenes ciudadanos. En otras palabras, sería chocante que un protagonista-niño hablara como un niño y no como un adulto.

Es curioso mencionar que en la traducción se reprodujo la forma de hablar particular del Imbécil. En español, el Imbécil se refiere a sí mismo en tercera persona y a menudo sus oraciones no contienen un objeto directo o un verbo:

12) El nene quiere como el Abu

(Lindo 1995: 68)

a) Baby wants like grapa (grapa is my grandpa)

(Lindo 1995/2009: 65, traducido por Travalia).

13) El nene guapo

(Lindo 1995: 70)

a) Baby handsome

(Lindo 1995/2009: 69, traducido por Travalia)

14) El nene quiere con Manolito hablando

(Lindo 1996: 76)

a) Baby wants with Manolito talking

(Lindo 1996/2010: 76, traducido por Travalia)

Se da por sentado que los lectores meta apreciarán que el Imbécil habla como un niño pequeño y, por lo tanto, no incide en la función didáctica del texto. Dicho de otro modo, los lectores no sentirán el deseo de imitar esta forma de hablar impropia.

Si bien el lenguaje de Manolito en la versión original se caracteriza por ser sobre todo coloquial, también revela palabras cultas intercaladas. El hecho de que Manolito, un niño de ocho años, utiliza palabras muy formales aporta ironía al texto. Conviene recordar que Manolito surgió de la radio como un niño que comentaba temas políticos y sociales desde una perspectiva inocente. A través de su interpretación simple del mundo adulto, ponía en evidencia las contradicciones de este último. Es precisamente la mezcla de inocencia, por un lado, y la perspicacia y madurez exageradas, por el otro, lo que hace que el Manolito original sea un personaje tan entrañable. En el texto meta muchas palabras cultas se suprimieron o se sustituyeron por términos más simples, lo cual redujo la personalidad de Manolito a la de un niño inocente.

Para la traducción del segundo libro, quisimos introducir en el discurso de Manolito palabras como subjected to (Lindo 1995/2009: 7, traducido por Travalia) y scroungier (Lindo 1995/2009: 49, traducido por Travalia) que la editorial eliminó, calificándolas de «too adult»y «too elevated», respectivamente. Junto a este último comentario, la editora añadió, "Alternative here would be 'messier'» (aunque al final se optó por scruffier) y "Other elevated language removed throughout».

Otros ejemplos del discurso formal que la editorial suprimió de la traducción de 2nd Volume (Lindo 1995/2009, traducido por Travalia) son:

- hereinafter;

- above-mentioned;

- concur;

- hence. 
Asimismo, muchas palabras del registro culto de Pobre Manolito se eliminaron o se sustituyeron por otros menos sofisticados:

CuAdRo 5

Palabras del registro culto

\begin{tabular}{|l|l|}
\multicolumn{1}{|c|}{$\begin{array}{c}\text { Pobre Manolito } \\
\text { (Lindo 1995) }\end{array}$} & \multicolumn{1}{c|}{\begin{tabular}{c}
\multicolumn{1}{c|}{ 2nd Volume } \\
(Lindo 1995/2009, traducido por Travalia)
\end{tabular}} \\
\hline impertérrito (p. 25) & unfazed (p. 21) \\
\hline implacable (p. 61) & [OMITTED] (p. 58) \\
\hline fisonomista (p. 70) & [OMITTED] (p. 68) \\
\hline mortífero (p. 97) & lethal (p. 97) \\
\hline indómito (p. 117) & rebellious (p. 118) \\
\hline engorroso (p. 132) & awkward (p. 135) \\
\hline
\end{tabular}

Estos cambios son sorprendentes si tenemos en cuenta que el Manolito inglés es mayor que el Manolito español, por lo que sería más lógico que tuviera un vocabulario más sofisticado. No obstante, la editorial insistía en que rebajar el nivel del idiolecto de Manolito era necesario para que el lector estadounidense lo entendiera mejor. Es cierto que el público meta es, en principio, más joven que el público origen. Lo indudable es que, con estos cambios, se renuncia a cierta complejidad y gracia de la personalidad del protagonista.

\subsubsection{Corrección del discurso}

Al desarrollo del personaje de Manolito contribuyen en gran medida los errores que este comete a la hora de intentar utilizar "palabras de adultos»:

- efecto gazebo (en vez de placebo) (Lindo 1995: 54)

- sinalábrico (en vez de inalámbrico o sinalámbrico) (Lindo 1996: 105)

- de comisos (en vez de decomisos) (Lindo 1996: 111)

Este rasgo discursivo es típico de los niños: oyen a los adultos decir ciertas palabras, pero no captan la pronunciación exacta y, cuando las intentan reproducir ellos, se equivocan. Como ya hemos visto en el apartado 2, Desmidt (2006: 86) explica que la traducción de una obra infantil debe seguir unas normas pedagógicas que dictan que el texto ha de ajustarse a las destrezas lingüísticas y al conocimiento conceptual del niño. En la versión inglesa, se redujeron estos descuidos, no solo porque restaban corrección al discurso sino también porque podían ser confusos. También influyó el hecho de que en algunos casos no encontráramos errores equivalentes en la lengua meta que permitiesen provocar el mismo efecto en el lector meta:

- efecto gazebo (Lindo 1995: 54) $\rightarrow$ gazebo effect (Lindo 1995/2009: 52, traducido por Travalia);

- sinalábrico (Lindo 1996: 105) $\rightarrow$ cell phone (Lindo 1995/2009: 107, traducido por Travalia);

- de comisos (Lindo 1996: 111) $\rightarrow$ OMITIDO (Lindo 1995/2009: 113, traducido por Travalia).

Como vemos, en vez de utilizar una variante equivocada de la palabra correspondiente cordless phone, reemplazamos sinalábrico por el concepto más actual de cell 
phone. Asimismo, suprimimos la palabra de comisos porque nos fue imposible encontrar una palabra equivalente que se pudiera manipular para crear el mismo tipo de error gracioso. Mantuvimos, en cambio, gazebo. La versión española cuenta con una nota a pie de página que clarifica el error de Manolito: «Manolito quiere decir placebo: sustancia sin valor medicinal que puede producir efecto curativo si el enfermo la toma creyendo que es una medicina eficaz» (Lindo 1995: 54). En el texto inglés, en vez de utilizar una nota a pie de página, señalamos el error al lector con la frase «Paquito Medina says this is really called the 'placebo' effect, but whatever» (Lindo 1995/2009: 52, traducido por Travalia). Dado que las notas a pie de página distraen al lector al obligarle a parar la lectura, el hecho de que la traducción haya eliminado la nota se puede considerar una mejora con respecto al texto origen.

Los lectores adultos de la versión original se divertían con estos errores de Manolito. No obstante, el público al que va dirigido la versión inglesa, los niños, no comprenderían estas referencias lingüísticas sofisticadas.

Algunos de los ejemplos que hemos visto en este apartado, como la reducción de palabras cultas y eliminación de errores de niño, representan cambios en el nivel discursivo cuya función era asegurar que el público meta entendiera el texto. Otros, incluidos los vocablos y estructuras coloquiales que se estandarizaron, servían para crear un modelo de lenguaje para los lectores. Debido a estas modificaciones, los libros ya no cuentan con uno de los aspectos que más los define y distingue de otras obras de su género: el discurso coloquial y expresivo que imita el lenguaje oral. Al mismo tiempo, se pierde la intención de la autora y se altera el efecto en el lector meta.

\section{Conclusiones}

En este estudio, hemos examinado ejemplos de purificación y corrección en las traducciones al inglés de tres libros de la serie de Manolito Gafotas. La existencia de una traductora previa del primer volumen de la saga impuso ciertas limitaciones sobre nuestras decisiones a la hora de trasladar la segunda y la tercera entrega al inglés. La editorial estableció que la serie iría dirigida exclusivamente a niños, presentaría un habla más estándar que los libros originales y sería más políticamente correcta en su contenido. Su función pasó de ser aquella de únicamente divertir a aquella de divertir y servir de buen modelo.

De acuerdo con el primer principio de Shavit (2006: 26) que el traductor de una obra infantil debe respetar, al trasladar la serie de Manolito Gafotas al inglés, el contenido fue modificado para ser apropiado y útil para el niño. Sin embargo, en este caso, fue la editorial quien impuso una serie de modificaciones para crear un texto meta aceptable. En primer lugar, la editorial insistió en que las referencias a la violencia se redujeran para no chocar al lector y para que este no creyera que eran socialmente aceptables. Asimismo, consideró los elementos escatológicos aceptables solo en cantidades limitadas y dictó que los comportamientos irrespetuosos se atenuaran a fin de que el lector no los imitara. Ciertas alusiones que la editorial temía que se interpretaran de forma sexual se eliminaron para proteger la inocencia del joven lector. Por último, las referencias consideradas ofensivas para diferentes grupos de personas sobre todo de otra raza o religión se mitigaron para promover la idea del respeto por el otro entre el público meta. En cuanto al lenguaje, la editorial aplicó la estandarización del registro y la corrección de errores con el propósito de presentar 
un modo de hablar estándar y digno de reproducción. En el caso del vocabulario elevado, este intermediario reclamó su supresión o sustitución por palabras más estándar, para crear un texto más comprensible para los lectores meta, de acuerdo con el segundo principio establecido por Shavit (2006).

La censura por parte de la editorial entró en conflicto con nuestra visión del futuro lector y con nuestro deseo de recrear para él una experiencia parecida a la que tuvimos nosotros cuando leímos los libros. Es cierto que, gracias a las purificaciones y las correcciones, la versión inglesa se adhiere a los valores conservadores y pedagógicos de la literatura infantil en los EE.UU. Si no se ajustara a dichos valores no habría sido posible publicarlo en este país. Sin embargo, las pérdidas con respecto al texto original son innegables. No solo la trama se ve afectada, sino también el protagonista, así como muchos otros personajes, todos los cuales experimentan un cambio de personalidad. Se renuncia al humor y al tono coloquial y oral. Se sacrifica la intención de la autora, su estilo y técnica narrativa. No solo se desaprovecha información cultural, sino que también se presenta una visión distorsionada de la cultura origen (Cámara Aguilera 2014: 40). En resumen, los libros pierden su originalidad y su esencia al adaptarse al paradigma de lo que se espera de un libro infantil en EE.UU. El resultado es una versión «edulcorada, [...] adulterada y censurada de la obra» (Cámara Aguilera 2014: 40) que enmarca al niño en una «burbuja», impidiendo que se desarrolle como persona y privándole de las connotaciones didácticas y pedagógicas que debería tener la obra.

A pesar de que la serie se ha ajustado a las normas ideológicas del sistema literario infantil en los EE.UU., las pérdidas que ha sufrido al cruzar el charco han sido en vano. La traducción de Manolito Gafotas al inglés se ha paralizado debido a las bajas ventas. La editorial cita como razones una estrategia comercial no suficientemente agresiva y la poca visibilidad de la autora en los EE.UU. para promocionar los libros. Aunque nos es imposible señalar los cambios impuestos por la censura como la causa principal de su poca distribución, lo cierto es que no aseguraron el éxito de la traducción inglesa de la serie.

\section{NOTAS}

1. La serie está compuesta por ocho libros (véase el anexo).

2. EFE (7 de noviembre de 2008): Manolito Gafotas ya habla inglés. ABC. Consultado el 20 de julio de 2017, <https://www.abc.es/hemeroteca/historico-07-11-2008/abc/Cultura/manolito-gafotas-yahabla ingles_911075301730.html>.

3. Entrevista con Elvira Lindo, autora de Manolito Gafotas, 18 de abril de 2013.

4. Como resultado de la actualización del texto, las pesetas se cambiaron a euros, las referencias a la cultura popular se sustituyeron por otras más modernas y se añadieron alusiones a la tecnología como los teléfonos móviles.

5. Hasta la fecha se han realizado tres traducciones.

6. Cámara Aguilera (2014) descubrió los objetivos que nos habíamos planteado al llevar a cabo la traducción gracias a una entrevista que dimos en 2008. Véase Moriarty, Joanne y Travalia, Caroline (2008): Las traductoras de Manolito Gafotas al inglés nos cuentan qué piensan de Manolito Gafotas. (Entrevista) Manolito Gafotas. Consultado el 20 de julio de 2019, <https://web.archive. org/web/20081021075724/http://www.manolitogafotas.es/entrevista/>.

7. Observatorio de la Lectura y el Libro (2015): Los libros infantiles y juveniles en España: 2014-2015. Ministerio de Educación, Cultura y Deporte. Consultado el 24 de julio de 2017, <https:// www.scribd.com/document/334587126/Los-libros-infantiles-y-juveniles-en-Espana-2014-2015>.

8. Khan, Iram (1999): The censorship of Canadian children's literature. Canadian Content. Consultado el 20 de junio de 2018, <http://www.canadiancontent.ca/issues/0699censor.html>. 
9. James, Erika L. (2011): Fifty Shades of Grey. Nueva York: Vintage Books.

10. Horn Book (26 de septiembre de 2016): Banned Books Week 2016. The Horn Book Inc. Consultado el 20 de junio de 2018, <https://www.hbook.com/2016/09/blogs/out-of-the-box/banned-booksweek-2016/>.

11. Kinney, Jeff (2006): Diary of a Wimpy Kid. Nueva York: Amulet Books.

12. Harding, Ben y Villelabeitia, Ibon (20 de diciembre de 2007): Spain bans parents from smacking children. UK Reuters. Consultado el 13 de julio de 2017, <http://uk.reuters.com/article/oukoeuk-spain-smacking-idUKL2035492220071220>.

13. Lindo, Elvira y Travalia, Caroline (2008): Encuentro de Elvira Lindo con la traductora de Manolito Gafotas al inglés, Caroline Travalia. XV Jornadas en torno a la Traducción Literaria, Tarazona, 1 de noviembre de 2008.

14. Israel, Julia (2008): Manolito Four-Eyes. Introduce your tween to this bestseller from Spain. Time Out New York Kids. 32. Consultado el 6 de marzo de 2011, <https://web.archive.org/web/ 20110222214006/http://newyorkkids.timeout.com/articles/books/29587/manolito-foureyes\#ixzz64 utpLuTY>.

15. Rico Martín, Ana María (16 de mayo de 2001): Manolito Gafotas, una lectura con gancho. Imaginaria. Consultado el 29 de marzo de 2011, <http://www.imaginaria.com.ar/05/1/manolito2. htm>.

\section{REFERENCIAS}

AzIz QADER, Nida (2010): La traducción de literatura infantil español-árabe: análisis traductológico comparado de la obra 'El pirata Garrapata en tierras de Cleopatra'. Tesis de doctorado, sin publicar. Granada: Universidad Granada.

Booth, David (2011): Censorship. In: Philip Nel y Lissa PAul, eds. Keywords for Children's Literature. Nueva York/Londres: New York University Press, 26-30.

CÁmara Aguilera, Elvira (2014): Traducción y asimetría: Manolito Gafotas y su traducción al inglés como ejemplo de intervencionismo. Anuario de Investigación en Literatura Infantil y Juvenil. 14:23-42.

Desmidt, Isabelle (2006): A Prototypical Approach with Descriptive Translation Studies. Colliding Norms in Translated Children's Literature. In: Jan VAN CoILliE y Walter P. Verschueren, eds. Children's Literature in Translation. Manchester: St. Jerome, 79-96.

Fourie, Denise y Dowell, David (2002): Libraries in the information age: An introduction and career exploration. Greenwood Village: Libraries Unlimited.

House, Juliane (2004): Linguistic Aspects of the Translation of Children's Books. In: Harald Kittel, Armin Paul Frank, Norbert Greiner et al., eds. An International Encyclopedia of Translation Studies. Vol. 1. Berlín: de Gruyter, 683-697.

Hunt, Peter (1997): Censorship and Children's Literature in Britain Now, or The Return of Abigail. Children's Literature in Education. 28(2):95-103.

Ingram, Peter G. (2000): Censorship and Free Speech. Burlington: Ashgate.

KLINGBerg, Göte (1986): Children's Fiction in the Hands of the Translators. Lund: Gleerup.

Lindal, Lena (2016): Manolito Gafotas traducido al ruso y al inglés: ¿crossover o no? Tesina de maestría, sin publicar. Oslo: University of Oslo.

Lorenzo, Lourdes (2014): Paternalismo traductor en las traducciones del género infantil y juvenil. Trans. 18:35-48.

MacLeod, Anne Scott (1983): Censorship and Children's Literature. Library Quarterly. 53(1):2638.

Marcelo Wirnitzer, Gisela (2015): Manolito en inglés. In: Nuria Pérez Vicente, ed. Manolito por el mundo: análisis intercultural de las traducciones al inglés, francés, alemán e italiano. Sevilla: ArCiBel, 31-79.

Mayoral Asensio, Roberto (1997): La traducción de la variación lingüística. Tesis de doctorado, sin publicar. Granada: Universidad de Granada.

Newmark, Peter (1993): Manual de traduccion. (Traducido del inglés por Virgilio Moya) Madrid: Cátedra. 
O'Connell, Eithne (2006): Translating for Children. In: Gilian Lathey, ed. The Translation of Children's Literature: A Reader. Clevedon: Multilingual Matters, 15-24.

O’Sullivan, Emer (2002): Comparing Children's Literature. German as a Foreign Language. 2:32-56.

O'Sullivan, Emer (2005): Comparative Children's Literature. Londres/Nueva York: Routledge. Oittinen, Riita (2000): Translating for Children. Nueva York: Garland.

Oittinen, Riita (2006): No Innocent Act: On the Ethics of Translating for Children. In: Jan VAN Coillie y Walter P. Verschueren, eds. Children's Literature in Translation. Manchester: St. Jerome, 35-46.

Pascua Febles, Isabel (2015): Ética y traducción social. La traducción de nuevos modelos literarios para niños. In: Gloria BAzzocchi y Raffaella Tonin, ed. Mi traduci una storia? Riflessioni sulla traduzione per l'infanzia e per ragazzi [¿Me traduces una historia? Reflexiones sobre la traducción para niños y jóvenes.]. Bolonia: Bononia University Press, 35-55.

ReIss, Katharina (1982): Sobre la traducción de libros infantiles y juveniles. Lebende Sprachen. 27(1):7-13.

Shavit, Zohar (2006): Translation of Children's Literature. In: Gillian Lathey, ed. The Translation of Children's Literature: A Reader. Clevedon: Multilingual Matters, 24-40.

STAN, Susan (1997): A Study of International Children's Picture Books Published in the United States in 1994. Tesis de doctorado, sin publicar. Ann Arbor: Universidad de Michigan.

Toury, Gideon (1995): Descriptive Translation and Beyond. Ámsterdam/Filadelfia: John Benjamins.

VAN CoIllie, Jan (2006): Character Names in Translation: A Functional Approach. In: Jan VAN Coillie y Walter P. Verschueren, eds. Children's Literature in Translation. Manchester: St. Jerome, 79-96.

Van Coillie, Jan y Verschueren, Walter (2006): Children's Literature in Translation: Challenges and strategies. Manchester/Kinderhook: St. Jerome.

West, Mark (1996/2004): Censorship. In: Peter Hunt, ed. International Companion Encyclopedia of Children's Literature. Abingdon/Nueva York: Routledge, 680-690.

\section{ANEXO}

La serie Manolito Gafotas y sus traducciones al inglés

Lindo, Elvira (1994): Manolito Gafotas. Madrid: Alfaguara.

Lindo, Elvira (1995): Pobre Manolito. Madrid: Alfaguara.

Lindo, Elvira (1996): ¡Cómo molo! Madrid: Alfaguara.

Lindo, Elvira (1997): Los trapos sucios. Madrid: Alfaguara.

Lindo, Elvira (1998): Manolito on the road. Madrid: Alfaguara.

Lindo, Elvira (1999): Yo y el Imbécil. Madrid: Alfaguara.

Lindo, Elvira (2002): Manolito tiene un secreto. Madrid: Alfaguara.

Lindo, Elvira (1994/2008): Manolito Four-Eyes. (Traducido del español por Joanne Moriarty)

Tarrytown: Marshall Cavendish.

Lindo, Elvira (1995/2009): Manolito Four-Eyes: The 2nd Volume of the Great Encyclopedia of My

Life. (Traducido del español por Caroline Travalia) Tarrytown: Marshall Cavendish.

Lindo, Elvira (1996/2010): Manolito Four-Eyes: The 3rd Volume of the Great Encyclopedia of My

Life. (Traducido del español por Caroline Travalia) Tarrytown: Marshall Cavendish.

Lindo, Elvira (2012): Mejor Manolo. Madrid: Alfaguara. 